\title{
Telomerase activity in bladder cancer tissue
}

\author{
AKIHIRO MORII, AKIRA KOMIYA, AKIOU OKUMURA and HIDEKI FUSE \\ Department of Urology, Graduate School of Medicine and Pharmaceutical Sciences for Research, \\ University of Toyama, Toyama 930-0194, Japan
}

Received July 13, 2009; Accepted September 4, 2009

DOI: 10.3892/etm_00000015

\begin{abstract}
Telomerase is a ribonucleoprotein enzyme that maintains telomeric DNA repeats at the end of chromosomes. Telomerase activity has been reported in many human cancers. The present study evaluated telomerase activity in bladder cancer tissue and investigated whether this activity is associated with tumor characteristics and prognosis in bladder cancer patients. Telomerase activity was investigated using the telomeric repeat amplification protocol (TRAP) in bladder tissue specimens from 81 patients, including 75 patients with bladder carcinoma and 6 patients with dysplasia or an inflammatory bladder lesion. Forty-nine of the 75 bladder cancer patients were found to be telomerase-positive, while 1 out of the 6 control specimens without carcinoma was telomerase-positive. Telomerase activity was correlated with lower grade and lower stage bladder cancer, but was not significantly associated with cancer-specific survival in the total population of bladder cancer patients. However, telomerase-positive patients among the patients with invasive and grade 3 tumors had an improved prognosis. Telomerase activity was observed in early-stage bladder cancer, and may be an indicator of prognosis in bladder cancer patients with advanced-stage and high-grade tumors.
\end{abstract}

\section{Introduction}

Telomeres are specialized structures at the ends of eukaryotic chromosomes that protect genomic DNA from degradation and end-to-end fusion, thereby maintaining chromosome stability (1). In humans, this telomeric DNA consists of tandem repeated hexanucleotids TTAGGG (2). These sequences are diminished with each round of normal somatic cell division (3). After a certain number of cell divisions, normal somatic cells eventually stop dividing. This senescent stage is thought to be the result of the reduction in telomeres (4).

Correspondence to: Dr Akira Komiya, Department of Urology, Graduate School of Medicine and Pharmaceutical Sciences for Research, University of Toyama, 2630 Sugitani, Toyama 930-0194, Japan

E-mail: komiya@med.u-toyama.ac.jp

Key words: bladder cancer, polymerase chain reaction enzymelinked immunosorbent assay, telomerase activity, prognostic factor
Telomerase is a ribonucleoprotein enzyme that maintains telomeric repeats at the end of telomeres to compensate for sequence loss during DNA replication. Telomerase activity is assumed to be involved in the maintenance of telomere length, and its reactivation is required for cell immortalization. Telomerase activity has been reported in many human cancers (5). One study reported a correlation between telomerase activity in bladder cancer tissue and tumor grade or stage (6). However, little is known regarding the association between telomerase activity in bladder cancer tissue and prognosis. Telomerase activity was measured using a PCR-enzymelinked immunosorbent assay (ELISA) in bladder lesions with or without carcinoma. The correlation between telomerase activity and grade, stage or cancer-specific survival was also evaluated, and the association between telomerase activity and recurrence-free survival was analyzed in primary superficial bladder cancer patients to determine the usefulness of telomerase activity for predicting recurrence after a transurethral resection.

\section{Materials and methods}

The present study was conducted on 81 subjects including 75 patients (57 males and 18 females; range 26-87 years) with bladder cancer and 6 patients $(5$ males and 1 female; range 59-79 years) with dysplasia or an inflammatory bladder lesion. Tissue specimens were obtained by cold-cup cystoscopic biopsies. Necrotic lesions were avoided and the biopsy was obtained from lesions located as deep as possible, particularly in advanced-stage bladder cancer. Each sample was sliced in two, with one part taken for a pathological examination and the other immediately frozen in liquid nitrogen to avoid RNA degradation or telomerase denaturation until the proteins were extracted. If a pathological analysis of the specimen revealed degenerative changes, the specimen obtained for the telomerase assay was abandoned. The tissue specimens were stored at $-80^{\circ} \mathrm{C}$ until assay. The bladder carcinomas were staged and graded according to the World Health Organization classification (7). Clinicopathological characteristics of the bladder cancer patients are shown in Table I.

Extraction. Bladder tissues specimens (10-100 mg) were washed once in ice-cold buffer $(10 \mathrm{mmol} / 1 \mathrm{HEPES}-\mathrm{KOH}$ $\mathrm{pH} 7.5,1.5 \mathrm{mmol} / 1 \mathrm{MgCl}_{2}, 10 \mathrm{mmol} / 1 \mathrm{KCl}$ and $1 \mathrm{mmol} / \mathrm{l}$ dithiothreitol) then homogenized with 50-200 $\mu \mathrm{l}$ of cold lysis buffer (0.5\% CHAPS, 10 mmol/1 Tris- $\mathrm{HCl} \mathrm{pH}$ 7.5, $1 \mathrm{mmol} / 1$ EGTA, $1 \mathrm{mmol} / 1 \mathrm{MgCl}_{2}, 10 \%$ glycerol, $5 \mathrm{mmol} / 1 \beta$-mercaptoethanol 
Table I. Clinicopathological characteristics of the 75 bladder cancer patients.

\begin{tabular}{lc}
$\begin{array}{l}\text { Follow up in months } \\
\text { (mean } \pm \text { SD, range) }\end{array}$ & $37.2 \pm 30.9(1-114)$ \\
Age (years) & $71.6 \pm 12.3(26-87)$ \\
Gender (no., \%) & \\
Male & $57(76.0)$ \\
Female & $18(24.0)$ \\
Stage (no., \%) & \\
Ta & $18(24.0)$ \\
T1 & $29(38.7)$ \\
T2 & $18(24.0)$ \\
T3 & $9(12.0)$ \\
T4 & $1(1.3)$ \\
Grade (no., \%) & \\
G1 & $9(12.0)$ \\
G2 & $41(54.7)$ \\
G3 & $25(33.3)$ \\
\hline
\end{tabular}

and $0.1 \mathrm{mmol} / \mathrm{l}$ phenylmethylsulfonylfluoride) until complete lysis, when the extracts were quickly chilled in liquid $\mathrm{N}_{2}$. After $25 \mathrm{~min}$ at $4^{\circ} \mathrm{C}$, the lysates were centrifuged at $16,000 \mathrm{~g}$ for $20 \mathrm{~min}$ at $4^{\circ} \mathrm{C}$. The supernatants were aliquoted, quickly frozen, and stored at $-80^{\circ} \mathrm{C}$ until assay. The protein concentrations of the extracts were measured using the Bradford method, with bovine serum albumin (BSA) as the standard (Bio-Rad, Ivry, France).

Telomerase assay. Extracts containing $6 \mu \mathrm{g}$ of protein were analyzed using a non-radioactive test based on the method described by Kim et al (8). A telomerase PCR-ELISA was performed according to the manufacturer's instructions (Boehringer Mannheim, Meylan, France). This non-radioactive method was based on the recently developed telomeric repeat amplification protocol (TRAP) assay (8). All extracts were treated with RNase. The results were visualized using a colorimetric method. Absorbance values were reported as the absorbance at $450 \mathrm{~nm}$ red against the blank (reference wavelength $630 \mathrm{~nm})$. The specimens were considered to be telomerase-positive when the difference in absorbance $(\Delta \mathrm{A}$; $\mathrm{A}_{450}-\mathrm{A}_{630}$ ) was $>0.2$ optical density (OD) units.

Statistical analysis. Statistical analysis was performed using the Mann-Whitney $U$ test and $\chi^{2}$-test to evaluate the significance of the differences between the patient groups. The Kaplan-Meyer method was used to summarize the distribution of cancer-specific survival and recurrence-free survival, and the log-rank test was used to evaluate individual factors with respect to these outcomes. P-values $<0.05$ were considered to be significant.

\section{Results}

Forty-nine of the 75 bladder cancer patients (65.3\%) were found to be telomerase-positive, as was 1 out of the 6 control specimens. There were significant differences $(\mathrm{P}<0.05)$ in telomerase activity among the control, superficial (pTa-pT1) and invasive

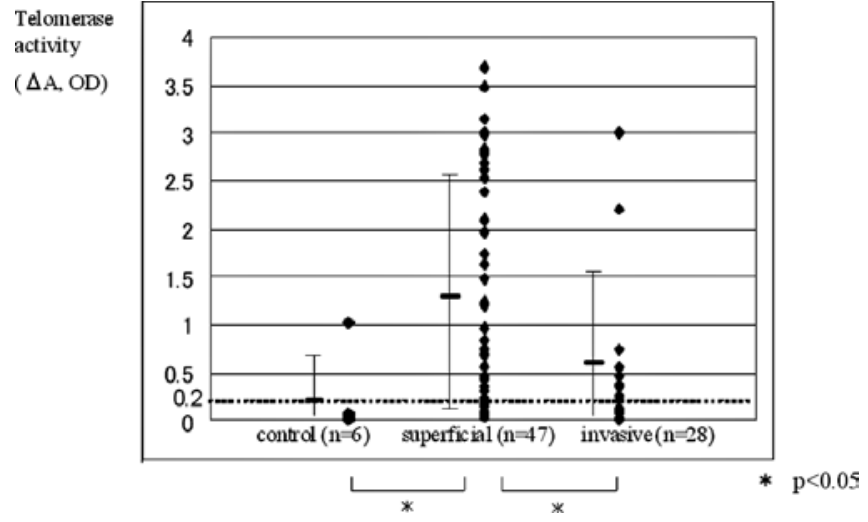

Figure 1. Telomerase activity according to stage. Telomerase activity was significantly low in cases of invasive bladder cancer.

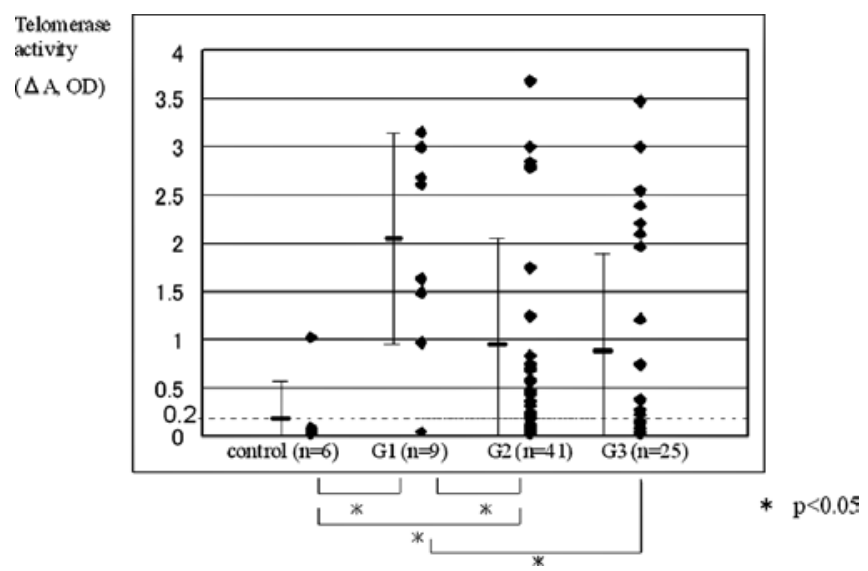

Figure 2. Telomerase activity according to grade. Telomerase activity was significantly low in high-grade tumors.

Table II. Comparison of tumor grade and stage with telomerase activity in bladder cancer using the $\chi^{2}$-test $(\mathrm{P}<0.05)$.

\begin{tabular}{lrrr}
\hline & & \multicolumn{2}{c}{ Telomerase activity } \\
\cline { 3 - 4 } Tumor & No. & Negative (\%) & Positive \%) \\
\hline Superficial & 47 & $10(21.3)$ & $37(78.7)$ \\
Invasive & 28 & $16(57.1)$ & $12(42.9)$ \\
Grade 1 & 9 & $1(11.1)$ & $8(88.9)$ \\
Grade 2 & 41 & $12(29.3)$ & $29(70.7)$ \\
Grade 3 & 25 & $13(52.0)$ & $12(42.9)$ \\
\hline
\end{tabular}

groups (pT2-pT4; Fig. 1), and among the control, low- and highgrade groups (control vs. G1; control vs. G2; G1 vs. G2; G1 vs. G3; Fig. 2). Only 1 positive patient in the control group had inflammatory lesions. Telomerase positivity according to stage was $79.7 \%$ for superficial and $42.9 \%$ for invasive carcinomas. Telomerase positivity according to grade was $88.9 \%$ for G1, $70.7 \%$ for G2 and $48.0 \%$ for G3 (Table II). The G1 tumor group had significantly higher telomerase positivity than the G3 tumor group, and the superficial group had significantly higher telomerase positivity than the invasive group. 


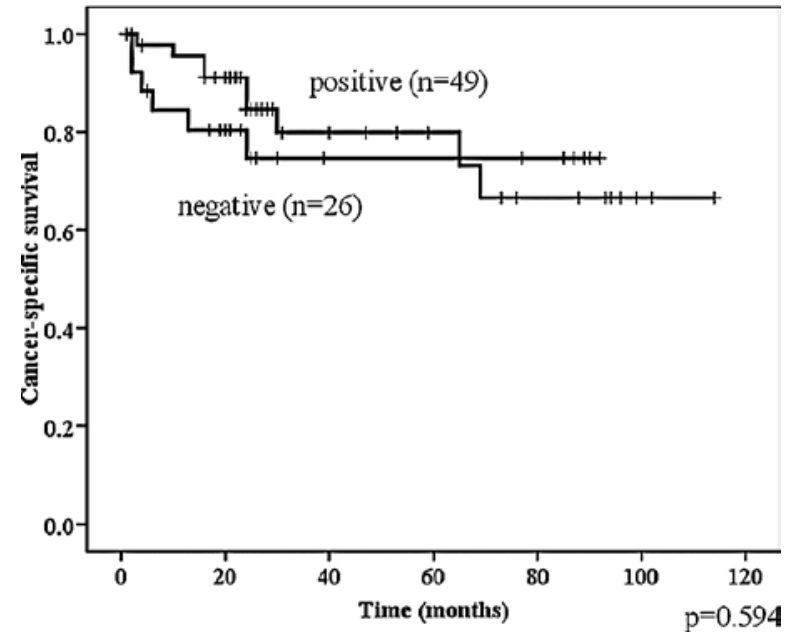

Figure 3. Correlation between telomerase activity and cancer-specific survival in bladder cancer patients. Telomerase activity was not significantly associated with cancer-specific survival.

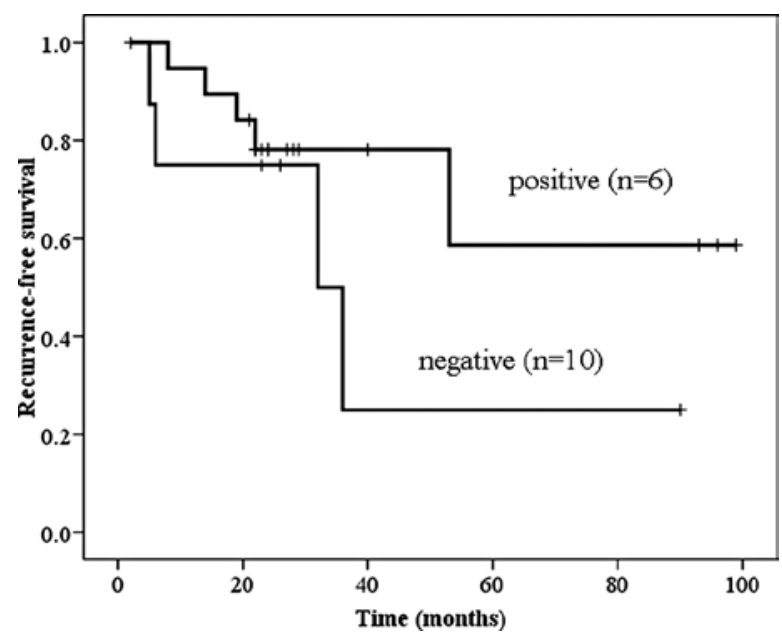

Figure 4. Correlation between telomerase activity and recurrence-free survival in patients with primary and superficial tumors. Patients exhibiting telomerase activity appeared to have a good prognosis, but the difference was not significant.

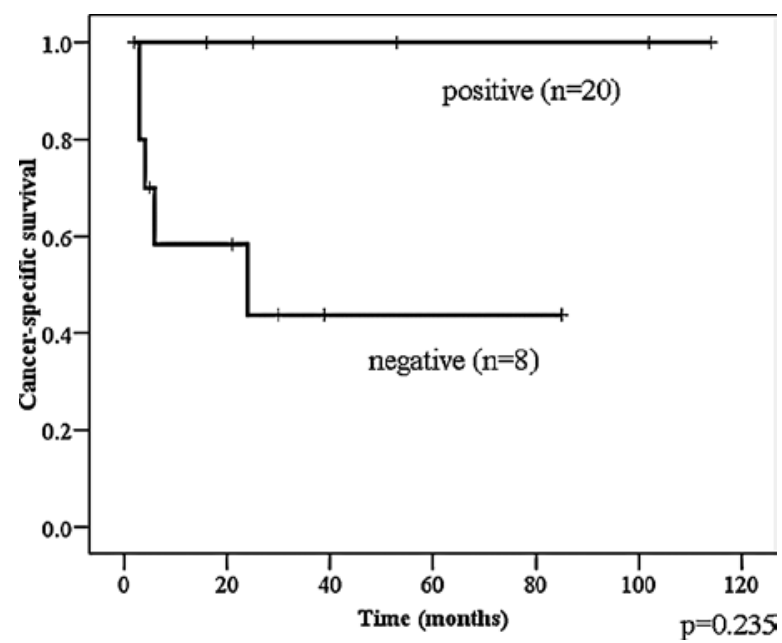

Figure 5. Correlation between telomerase activity and cancer-specific survival in patients with invasive and grade 3 tumors. Patients with telomerase-positive bladder cancer had a relatively good prognosis.
Telomerase activity was not significantly associated with cancer-specific survival in the total population of bladder cancer patients (Fig. 3). Telomerase-positive primary superficial bladder cancer patients tended to have a good prognosis with regard to recurrence-free survival; however, the difference was not significant (Fig. 4).

Six of 16 patients with invasive and grade 3 tumors were telomerase-positive; all 6 patients had a relatively good prognosis (Fig. 5).

\section{Discussion}

Telomerase activity is detected in a high percentage of tumors and in over $80 \%$ of human tumor specimens in vivo (9). Telomerase is apparently reactivated in tumors, and telomerase activity may play a role in the tumorigenic process (10).

Telomerase activity was observed in most tumor samples, a finding consistent with previous studies on bladder cancer $(6,8,11-14)$. The detection of telomerase activity in exfoliated urothelium is useful in the diagnosis of bladder cancer, as well as in the early detection of bladder cancer recurrence in the follow-up cases $(11,15)$.

An association between telomerase activity and pathological grade or stage in bladder cancer patients has also been demonstrated $(5,6,12)$. Lin et al reported that the expression of telomerase activity was clearly associated with pathological grade and stage (12). Tumors with high telomerase activity were characteristically accompanied by a high grade and advanced stage. Takihana et al also demonstrated that the expression of human telomerase reverse transcriptase (hTERT) mRNA was correlated with the progression of stage and grade in bladder cancer (10).

However, in the present study, low telomerase activity was found in advanced-stage and high-grade tumors, whereas high telomerase activity occurred in early-stage and low-grade tumors. Lancelin et al reported that the absence of telomerase activity in three tumor extracts was not correlated with low tumor grade (5). In their report, an inhibition of telomerase activity was observed in the PC3 (telomerase-positive) cell line upon its incubation with telomerase-negative cancer extract during the telomere elongation phase. The authors noted that this result indicated the presence of telomerase inhibitor in the tumors. However, the mechanisms behind this inhibition of telomerase activity remain unclear.

The present data were consistent with the findings of Lancelin et al (5). Telomerase activity may therefore play an important role in malignant alteration, but is not necessarily associated with tumor invasiveness and progression.

Certain studies have demonstrated that high telomerase activity is correlated with tumor progression and poor outcome in other types of tumors (16-18). Tatsumoto et al reported that the up-regulation of telomerase activity is an independent prognosis-associated factor in patients with colorectal cancer (16). Marchetti studied telomerase activity in 118 stage I nonsmall cell lung cancer patients (17), and observed that telomerase activity was a significant predictor of overall survival in these patients. In addition, in the same series of patients, telomerase activity was a marker of disease-free survival.

By contrast, other reports noted that tumors with low telomerase activity had a poor prognosis $(9,19,20)$. Kawanishi 
et al analyzed telomerase activity in 122 surgical Stage II specimens of colorectal carcinoma (19). The prognosis was found to be worse for patients with telomerase-negative tumors than for patients with telomerase-positive tumors. The authors assumed that the alternate telomerase-independent pathway is activated in telomerase-negative tumors, and that the alternative pathway represents the predominant mechanism for cellular transformation. It has been suggested that the mechanism by which this pathway leads to immortalization involves telomere elongation and stabilization via chromosomal translocation and recombination. Accordingly, telomerase-negative cells are expected to possess a more aggressive, genetically unstable phenotype.

In the present study, increased telomerase activity was not significantly associated with cancer-specific survival in the bladder cancer patients. However, patients positive for telomerase activity did appear to demonstrate a good prognosis, in particular those patients with invasive and grade 3 tumors. Consequently, in these patients, telomerase activity may be useful as prognostic marker. In this study, the number of patients with invasive and grade 3 tumors was small. To elucidate the association between telomerase activity and prognosis, future studies with a large sample number are required.

In conclusion, telomerase activity may be useful for predicting the prognosis in patients with a particularly high stage or high grade of bladder cancer. Patients with low telomerase activity tumors may have a poor prognosis.

\section{References}

1. Blackburn EH: Structure and function of telomerase. Nature 350: 569-573, 1991.

2. Moyzis RK, Buckingham JM, Cram S, et al: A highly conserved repetitive DNA sequence (TTAGGG) $\mathrm{n}$, present at the telomere of human chromosomes. Proc Natl Acad Sci USA 85: 6622-6626, 1988.

3. Hastie ND, Dempster M, Dunlop MG, Thompson AM, Green DK and Allshire RC: Telomerase reduction in human colorectal carcinoma and with aging. Nature 346: 866-868, 1990.

4. Allsopp RC, Vaziri H, Patterson C, et al: Telomere length predicts replicative capacity of human fibroblasts. Proc Natl Acad Sci USA 89: 10114-10118, 1992.

5. Lancelin F, Anidjar M, Villette JM, et al: Telomerase activity as a potential marker in a preneoplastic bladder lesions. BJU Int 85: 526-531, 2000.
6. Okumura A, Mizuno I, Nagakawa O and Fuse H: Telomerase activity is correlated with lower grade and lower stage bladder carcinoma. Int J Urol 11: 1082-1086, 2004.

7. Mostofi FK, Davis CJ and Sesterhenn IA: Histological Typing of Urinary Bladder Tumours. 2nd edition. Springer, Berlin, 1999.

8. Kim NW, Piatyszek MA, Prowse KR, et al: Specific association of human telomerase activity with immoral cells and cancer. Science 266: 2011-2015, 1994.

9. Rossi A, Russo G, Puca A, et al: The antiretroviral nucleoside analogue Abacavir reduces cell growth and promotes differentiation of human medulloblastoma cells. Int J Cancer 125: 235-243, 2009.

10. Takihana Y, Tsuchida T, Fukasawa M, Araki I, Tanabe N and Takeda M: Real-time quantitative analysis for human telomerase RNA component mRNA expression an markers for clinicopathologic parameters in urinary bladder cancer. Int J Urol 13: 401-408, 2006.

11. Bravaccini S, Sanchini MA, Granato AM, et al: Urine telomerase activity for the detection of bladder cancer in females. J Urol 178: 57-61, 2007.

12. Lin Y, Miyamoto H, Fujinami K, et al: Telomerase activity in human bladder cancer. Clin Cancer Res 2: 929-932, 1996.

13. Zhang B. Bai YX, Ma H, et al: Silencing PinX1 compromises telomere length maintenance as well as tumorigenicity in telomerase-positive human cancer cells. Cancer Res 69: 75-83, 2009.

14. Lee DH, Yang SC, Hong SJ, Chung BH and Kim IY: Telomerase: a potential marker of bladder transitional cell carcinoma in bladder washes. Clin Cancer Res 4: 535-538, 1998.

15. Eissa S, Swellam M, Ali-Labib R, Mansour A, El-Malt O and Tash FM: Detection of telomerase in urine by 3 methods: evaluation of diagnostic accuracy for bladder cancer. J Urol 178: 1068-1072, 2007.

16. Tathumoto N, Hiyama E, Murakami Y, Imamura Y, Shay JW, Matsuura Y and Yokoyama T: High telomerase activity is an independent prognostic indicator of poor outcome in colorectal cancer. Clin Cancer Res 6: 2696-2701, 2000.

17. Marchetti A, Bertacca G, Buttitta F, Chella A, Quattrocolo G, Angeletti $C A$ and Bevilasqua $G$ : Telomerase activity as a prognostic marker indicator in stage I non-small cell lung cancer. Clin Cancer Res 5: 2077-2081, 1999.

18. Hiyama E, Yokoyama T, Tatsumoto N, Hiyama K, Imamura Y, Murakami Y, Kodama T, Piatyszek MA, Shay JW and Matsuura Y: Telomerase activity in gastric cancer. Cancer Res 55: 3258-3262, 1995.

19. Kawanishi TR, Lopez F, Fratantonio S, Kim N, Goldblum J, Tubbs R, Elson P, Lavery I, Bukowski RM, Ganapathi R and Ganapathi MK: Telomerase activity in stage II colorectal carcinoma: Telomerase negative tumors are correlated with poor prognosis. Cancer 95: 1834-1839, 2002.

20. Nooredin Z, Lina F and Annika D: Weak telomerase activity in malignant cells in metastatic serous effusions. Acta Cytologica 51: 412-416, 2007. 